\title{
Monitoring the exhaust air of a compost pile as a process variable with an e-nose
}

A.C. Romain, D. Godefroid, M. Kuske, J. Nicolas

Département des Sciences et Gestion de l'environement, Unité Surveillance, Université de Liège, Arlon, Belgium

\begin{abstract}
In this paper, the monitoring of the composting process with an e-nose is presented. An emission chamber is developed for this purpose and put on a household waste compost pile. A lab-made e-nose with metal oxide sensors is located at the exit of this chamber. Simultaneously to the e-nose measurements, air sampling on sorbent tubes as well as physico-chemical analysis are realised. The adsorbed air samples are analysed in the lab by gas chromatography coupled to mass spectrometry (GC-MS). In addition, some parameters of the composting process are collected (compost temperature, age of the pile, date of the aeration). Correlation between the sensors and 14 chemical families is determined by principal component analysis (PCA). By canonical analysis, two models are developed and calibrated by the proportion of each chemical family and in function of the compost process events. Thanks to these models, monitoring of various kinds of compost process events is possible with only one measurement device.
\end{abstract}

Keywords: e-nose; Compost; Monitoring; Emission chemical composition

\section{Introduction}

The environmental monitoring is a very promising field of applications for the electronic nose. The objective is to assess the odour annoyance, as an indicator of life quality ${ }^{[1]}$. The odorous pollution is one of the most important factor of harmony between a company and its neighbourhood ${ }^{[2,3]}$. In that frame, the monitoring of the emission with an electronic nose could be used for malodours pollution control ${ }^{[4]}$ but also for a real time management of an odour abatement technique. It could also aim at a better understanding of the odour release and relate this emission to the composting process ${ }^{[5]}$.

The composting of organic waste material generates compounds emission in the air. The composition of the exhaust air is indicative of the composting process ${ }^{[6]}$ and of the quality of the compost. For instance, under anaerobic conditions, specific compounds are released like carboxylic acids and ammonia ${ }^{[7]}$. A better aeration of the product can minimise the emissions and improves the quality of the compost.

The composting efficiency is function of various parameters and some of them are uncontrollable. Anyway, a good management should require numerous measurements of different variables. Spotted measurements of temperature, traditionally realised, are easy but not sufficient to detect abnormal events. The other variables like $\mathrm{pH}, \mathrm{O}_{2}$ level and humidity are also important. Continuous measurements of all these parameters would be useful ${ }^{[8]}$. In addition, some laboratory chemical analyses of the compost and of the odour emission are needed. But they are expensive, complex, no rapid and not realised in real time.

Electronic nose has indeed a huge potential for noninvasive on-line monitoring of processes in general, and especially of biological processes ${ }^{[9]}$. It can give a rapid signal integrating various parameters.

The manager needs a fast method for on site detection of stress events like anaerobic conditions. A real time continuous measurement could also enhance the composting operations, for example in determining the turning time of the compost piles. There is also a potential interest for the customer of the compost. Thanks to the monitoring of the compost piles, he could know the "story" of the compost and receive information on the tracability of the product. A better understanding of the components release is also possible thanks to a continuous measurement of emissions. The emission could be related to the process in order to highlight the factors governing it.

The objective of this work is to verify that the gas emission of a pile is an index of the composting process. In addition, it aims at studying the behaviour of an electronic nose system towards variation of complex mixture of compounds in the field and to calibrate the e-nose signals with chemical analyses of the compost emission. In order to fulfil this aim, it was required to isolate the emission of the pile from the polluted odorous ambient air. So an emission chamber was developed in order to avoid external contamination. This chamber permits also the determination of compounds emission rate $\left(\mu \mathrm{g} / \mathrm{m}^{2} \mathrm{~s}\right)$. However, these data are not considered in this paper. Our field electronic nose is coupled to this chamber. A lab-made dilution device is also located in front of the 
electronic nose to avoid saturation of the sensors. The apparatus allows simultaneously e-nose measurement and physico-chemical analyses.

\section{Material and methods}

\subsection{Compost pile}

One compost pile of the Belgium Habay city composting facility is studied. The compost deposit area is situated under a shelter. Typically, six to eight windrows are located in the area in various stages of composting. The pile of interest is constituted of household wastes with organic and inorganic material. The creation of the studied pile lasted 23 days. The final pile size is about $2.5 \mathrm{~m}$ high and $50 \mathrm{~m}$ length. The volume of garbage put on the pile is about $1882 \mathrm{~m}^{3}$. The compost is aerated by turning the pile with a maximum frequency of twice a week. The composting process under the shelter lasts 8 weeks during which the compounds emission varies. Compost emissions are not analysed in the lab. The measurements of the gas emission are performed directly on the pile in the shelter.

\subsection{Emission chamber and instrumentation}

An emission chamber was developed to confine the gas generated by the compost pile and to avoid the influence of external parameters. The work of Wang et al. (2001) ${ }^{[10]}$ about a wind-tunnel sampling system guided the development of this chamber. It is a wood box roofed by Tedlar ${ }^{\circledR}$ sheet (Fig. 1). It is $0.25 \mathrm{~m}$ in height, $1.40 \mathrm{~m}$ long and $0.40 \mathrm{~m}$ wide, which gives a covered area of $0.56 \mathrm{~m}^{2}$. This surface corresponds to about $0.4 \%$ of the area of one of the two lateral sides of the pile. One of the two larger rectangular surfaces of the chamber is left open. This open side of the chamber is put on a metal structure penetrating into the compost surface. A fan in the middle of the chamber insures the inner ventilation.

This chamber is placed along one side of the pile with the outlet at the top. The chamber outlet is a $10 \mathrm{~cm}$ diameter chimney.

The air velocity is measured in the middle of the outlet chimney with an anemometer and a data logger (Testo Inc, Germany) during each sampling period: average velocity is $0.3 \pm 0.1 \mathrm{~m} / \mathrm{s}$. The flow rate determined by multiplying the air velocity by the cross-section of the chimney is $8.5 \mathrm{~m}^{3} / \mathrm{h}$. Emission rate is calculated by dividing the flow rate through the chimney by the surface area covered by the chamber. The emission rate of this compost pile is about $15 \mathrm{~m}^{3} / \mathrm{m}^{2} \mathrm{~h}$. Such high emission rate prevents the use of a carrier gas, for which we should provide an excessive flow rate.

The emitted chemical compounds are adsorbed on sorbent tubes filled with a dual bed of Tenax ${ }^{\mathrm{TM}}$ TA/Spherocarb ${ }^{\mathrm{TM}}$ (Markes trademark), pulled by a calibrated sampling pump (Gilian $\left.{ }^{\circledR}\right)$. The sorbent tube is connected to a backup tube in order to control the breakthrough volume (the capacity of the sampling tube). The pump is connected to the chimney by Teflon tubing. The sampling flow is $0.10 \mathrm{Nl} / \mathrm{min}$ and the collecting time is 2 min.

Electronic nose measurements are realised with a flow of $200 \mathrm{ml} / \mathrm{min}$. The nose is connected to the chimney by another Teflon tubing. Before inflowing to the e-nose, the pumped air enters into a small dilution stainless box to avoid sensors saturation (Fig. 2). Dilution ratio of nine is realised with dry pure air and two rotameters.

In addition to these samplings, temperature and humidity of the air flowing in the chimney are recorded. 
Fig. 1: Photography of the emission chamber used in this study

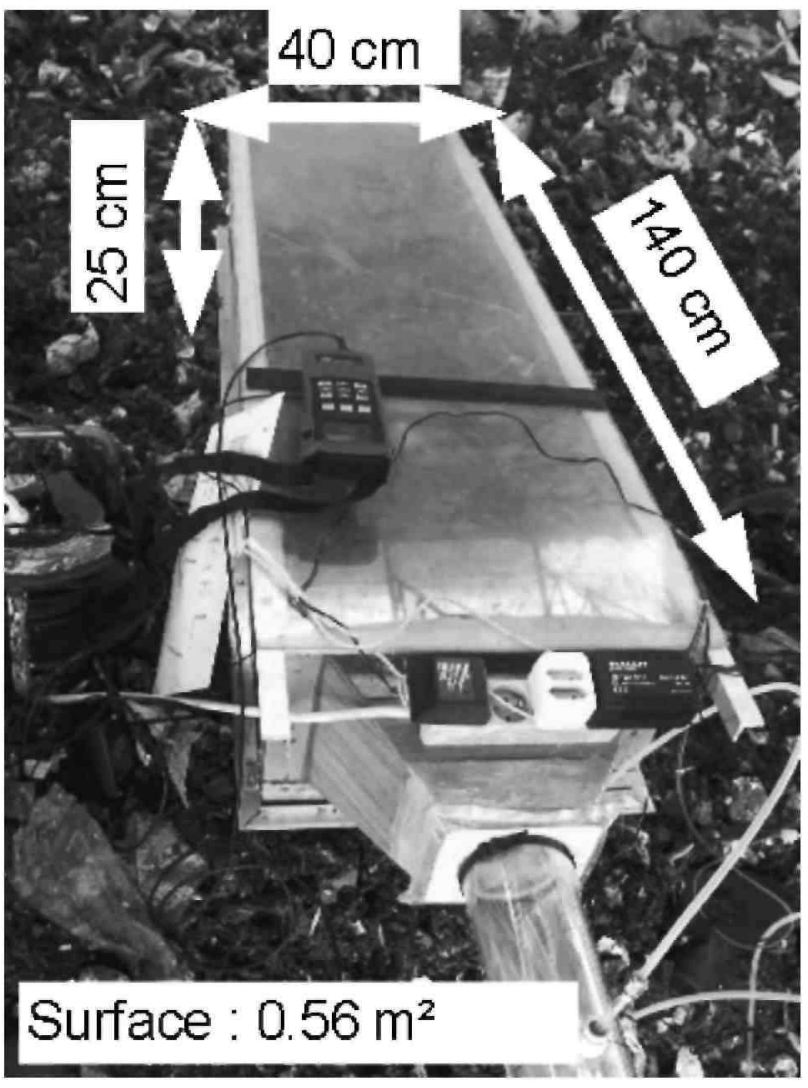

\subsubsection{Self made electronic nose}

A self-made electronic nose is used in the field. It consists in a battery powered sensor array and a PC board, with a small keyboard and a display. Seven metal oxide sensors are placed in two $200 \mathrm{~cm}^{3}$ stainless steel boxes: four sensors from "Figaro" (TGS880, TGS822, TGS2610 and TGS842) in the first chamber and three sensors from "Capteur" (CAPO1L, CAP02L, and CAP25) in the second chamber. At the beginning of the campaign, eight sensors were used but one of them, CAP06, was quickly damaged by the harsh conditions. In both chambers, the temperature and the relative humidity are measured and recorded by the system. A small pump controlled by the computer code sucks up the ambient air through a Teflon tubing with a flow rate of $200 \mathrm{ml} / \mathrm{min}$. Data are recorded in the local memory and downloaded in an external computer to be off-line processed by statistical and mathematical tools (Statistica and Matlab).

Fig. 2: Schematic diagram of the dilution chamber.

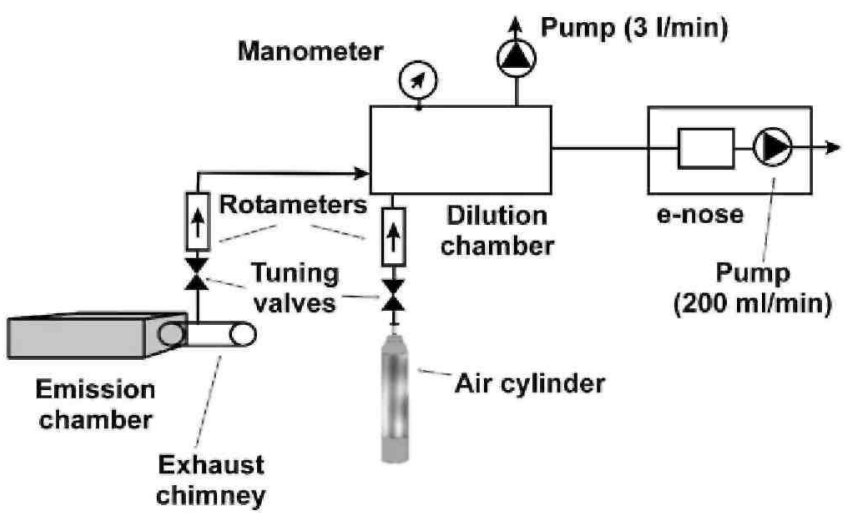




\subsubsection{Physico-chemical measurements}

Compost temperatures are taken approximately at the middle of the compost height using a thermocouple probe placed at 30 and $70 \mathrm{~cm}$ depth.

Colorimetric tubes (Dräger®) are used for the detection of ammonia and hydrogen sulphide in the exhaust of the chimney.

In parallel, VOC's are sampled on Tenax ${ }^{\mathrm{TM}}$ and Spherocarb ${ }^{\mathrm{TM}}$ tubes and then desorbed using a thermal desorber (UNITY ${ }^{\mathrm{TM}}$ from Markes International) linked to a gas chromatograph coupled to mass spectrometer (Agilent HP6890 GC and 5972 MS). The carrier gas is helium and a split ratio of five is applied on the sorbent tube. The column CP-Sil 8 CB MS used (5\% phenyl 95\% dimethylpolysilox-ane) (Chrompack) has a length of $50 \mathrm{~m}$, a $0.25 \mathrm{~mm}$ internal diameter and a film thickness of $0.4 \mu \mathrm{m}$. Running conditions for GC are : initial temperature $38^{\circ} \mathrm{C}$, initial time $7 \mathrm{~min}$; rate $5^{\circ} \mathrm{C} / \mathrm{min}$, final temperature $250{ }^{\circ} \mathrm{C}$, and final time $5 \mathrm{~min}$. The MS transfer line is at $280{ }^{\circ} \mathrm{C}$ and the mass scan range is from 29 to 300 . External standard solutions are introduced directly as liquids $(0.5 \mu \mathrm{l})$ onto the rear of a single bed Tenax ${ }^{\mathrm{TM}}$ tube. The solutions consist of heptanal, butylacetate, ethylbutyrate, limonene with a concentration of 40, 400, and $2000 \mathrm{ng} / \mu \mathrm{l}$ in hexane. GC-MS peak identification is realised by the HP chemstation software and the NIST 1992 mass spectrum database. The samples are analysed in the lab within maximum $4 \mathrm{~h}$ after the sampling.

\subsubsection{Methodology}

The measurement campaign lasted 2 months. It began on 8 April and finished on 6 June 2003. At least one measurement per week was accomplished during this period. Reproducibility tests of the measurement are also realised.

The emission chamber was put into the compost windrow surface just before the measurements. After each day of experiment the chamber was located in a ventilated odourless room in order to clean it. The e-nose measurement was carried on during maximum $1 \mathrm{~h}$. No odourless reference air was used. The sampling was continuous with an acquisition interval of $30 \mathrm{~s}$. Simultaneously to the e-nose operation, other parameters were recorded: temperature of the compost pile, humidity and temperature of the emission and air velocity in the chimney. Colorimetric analyses and air sampling were also realised during this time.

In addition some process information was collected like the last turning day and the compost age.

\section{Results}

A total of 10 days of measurement are used to investigate the relations between the e-nose measurement, the chemical analysis and the process information.

About two hundreds compounds are identified in each sample. They correspond to 14 chemical families. In order to study potential relations between the e-nose response and the chemical composition of the emission, it is required to consider the chemical families rather than the individual compounds. Indeed, the sensors are not compounds specific but they are sensitive to chemical class like alcohols or general combustible gases. Excepted some individual substances like acetaldehyde, with a garbage smell, the families are also more specific to the compost process ${ }^{[11]}$. In this paper, the aim is to find qualitative information concerning the compost process thanks to the e-nose and not to detail and to interpret the emission rate of pollutants or of odours. Further paper on this topic is envisaged. Thus, for qualitative purpose, we used normalised sensors signals $\quad\left(R_{i j} / \sqrt{\Sigma_{k=1}^{m} R_{i k}^{2}}\right)$

and the relative proportion of each identified chemical family rather than the absolute concentration, which is more related to the quantitative information of the e-nose response. The proportion is calculated by adding the masses of all the compounds belonging to the considered family and by dividing this value by the total mass of all the compounds identified in the sample. The results are presented versus the compost age in Fig. 3 for 12 families.

On this figure, it is clear that the alcohol family prevails during all the composting process time except in the earlier stages (day 11 and day 17). At this stage, the aliphatic and aromatic hydrocarbons compounds that are inherent of the waste are the most abundant. A decrease of these two families is then observed when the temperature pile increase. But sudden changes of some families are observed: a peak of nitrogen compounds and carboxylic acids appears the 17th day, a high increase of the ketones and furans occurs the last days of 
composting and a peak of alcohol is observed the 21 st. These "events" can be explained by process parameters. The 17th day there was a stress due to the absence of aeration: there was no turning of the pile since 5 days. The 21 st day, the measurement was realised after the turning of the pile. The furans and ketones are substances released by purely chemical reactions inside the compost (abiogenic substances) and are not issued from the micro-organisms degradation (biogenic substances). Then the emergence of these families at the end of the thermophilic phase and at the start of the maturation phase is not surprising.

Fig. 3: Evolution with compost age of relative proportion of 12 chemical families.
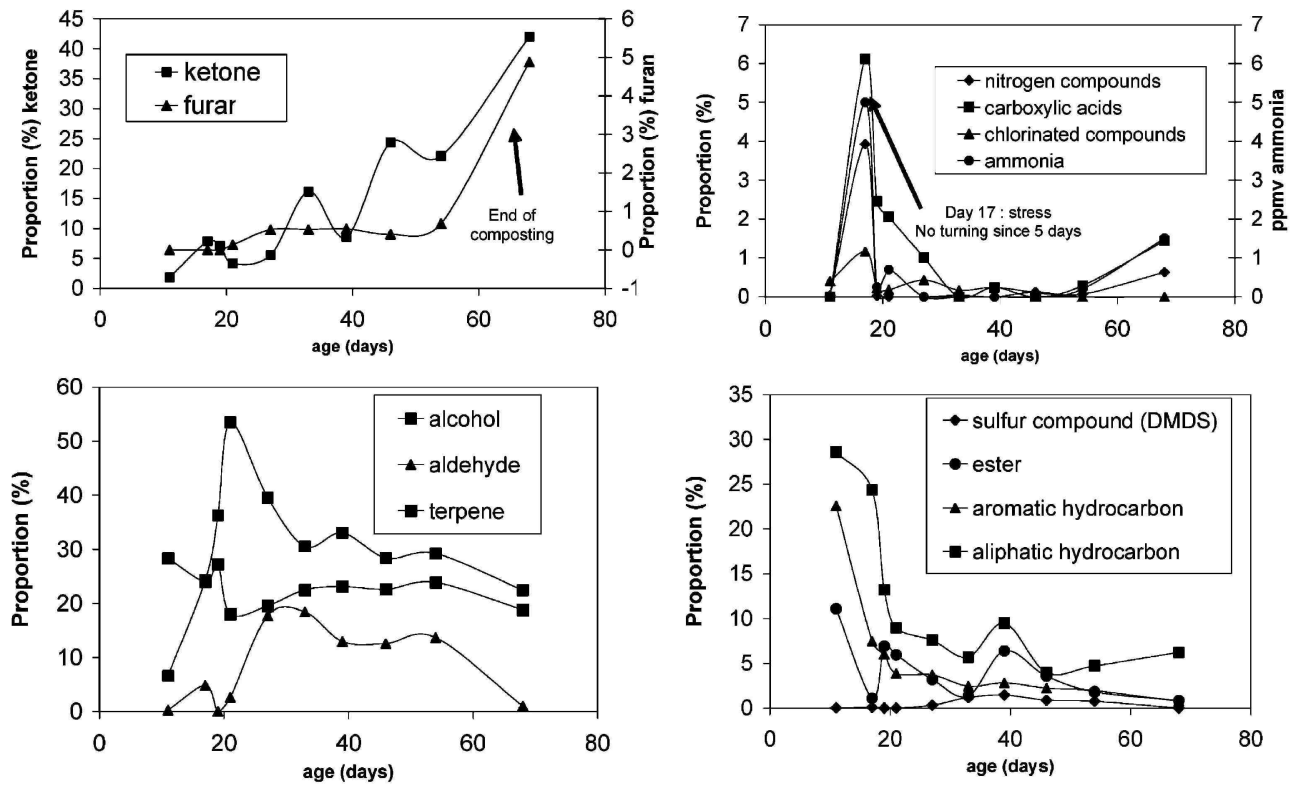

The question is: is the e-nose able to "see" these events and to identify them ?

First, exploration of the observations are made by principal component analysis (PCA) in order to highlights some correlation between the sensors and the chemical families.

PCA was performed with the whole set of variables, including both the normalised sensor signals and the relative mass of the chemical families. Concerning the sensor signal values, the data set used for this statistical analysis and for the following ones is a subset of the continuous observation file, containing 15 randomly selected observations for each day.

The sensor signal variables are the sensor resistances normalized separately: the four TGS with respect to TGS resistances and the "Capteur" with respect to the "Capteur" resistances. The sensor responses that are input into the statistical procedures are the normalized signals or their complement to one so that they always increase in the presence of the odorous gas.

The chemical data set is constituted of the proportional values of the families: sulphur compounds, alcohols, nitrogen compounds, aldehydes, ketones, esters, acids, furans, dioxins, ethers, terpenes, chlorinated compounds and hydrocarbons. As only one air sampling is taken per measurement day, the same chemical data is supplied for the 15 e-nose signal values selected.

Fig. 4 shows the plot of loadings in the plane of the two first components.

As expected, TGS842, which is sensitive to methane and exhibits a low sensitivity to alcohol vapours is on the right part of the diagram, close to hydrocarbons and terpens and far from alcohols. On the left, TGS822, more sensitive to alcohols and organic solvents is close to alcohol, aldehydes and sulfur compounds. We can also notice that the three "Capteur" sensors are close the ones to the others and do not explain much variance. Concerning the clustering of the chemical families, we may point out that chloride, acids, nitrogen compounds and ammonia belong to the same group, as they appear together on day 17. Furans and ketones, which appears more at the end of the composting process form an other group. The group with alcohols, sulphur compounds, aldehydes and dioxins is more representative of the intermediate thermophile period. 
Fig. 4: Plot of loadings in the plane of the two first factors of a PCA carried out with both sensor signals and relative chemical concentrations.

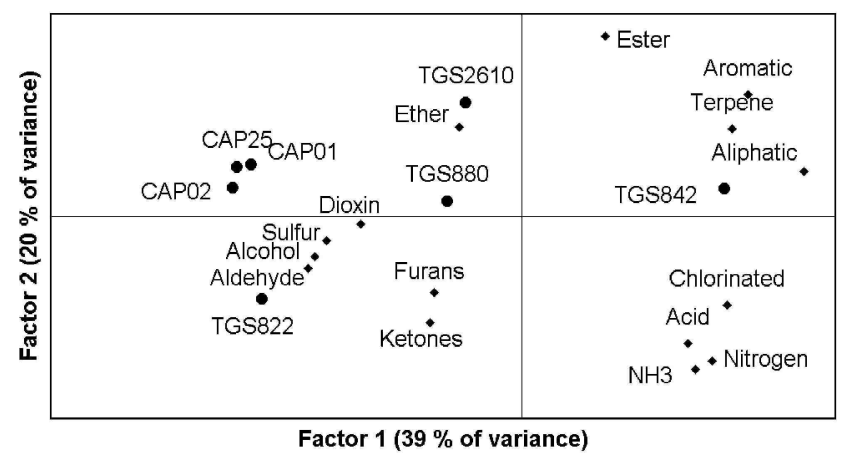

Fig. 5: Evolution of the quadratic mean of the seven sensor resistances vs. compost age.

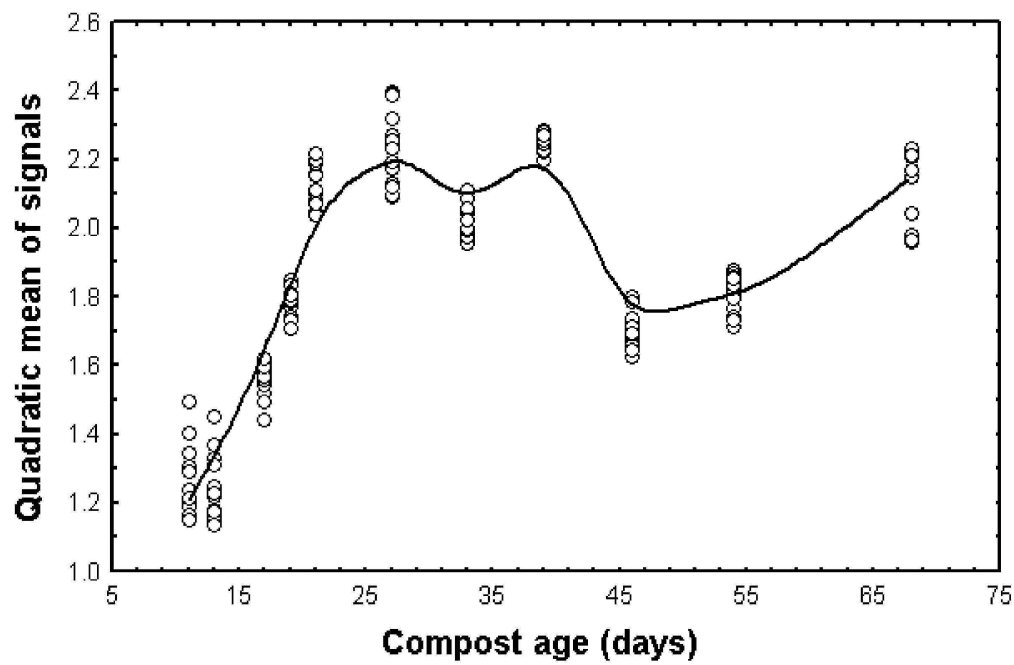

As seen on the plots of the evolution of the chemical composition with the age of the compost pile (Fig. 3), some chemical families appears indeed in the middle of the composting process, some others at the beginning of the self heating phase and others at the end of the maturation phase. So, a single sensor signal cannot represent an adequate indicator of the whole process evolution. For example, TGS2610 response decreases at the end of the composting process while CAP01 response grows at the same time.

That is an advantage of using an array of sensors. As an illustration of such advantage, Fig. 5 shows the evolution of an indicator of the global "intensity", as measured by the quadratic mean of the seven sensor resistances. The global array response firstly grows during the first days of the composting process, then it reaches a stabilisation phase, then it decreases. But, just at the end of the maturation phase, the global response grows again because some sensors are sensitive to the chemical compounds appearing only at that moment.

Such indicator could be used to assess the global emission level, but it could not point out any specific event occurring during the composting process.

Then, more specific indicators of composting process evolution were developed using canonical correlation analysis. Such analysis aims at studying the relationship between two sets of variables, each of which being able to contain several variables. The purpose of that procedure is to summarize or explain the relationship between the sets of variables by finding a small number of linear combinations from each set that have the highest correlation possible between the sets. The first combinations of each set are generally selected, as their correlation coefficient is the higher. 
In our case, the first set of variables contains the signals of the seven gas sensors and the second set contains the proportional value of some selected chemical families.

A first indicator is constructed by relating the sensor signal to the compounds emitted during a "stress" phase, when the compost pile needs to be turned (the 17th day). Those are ammonia nitrogen compounds, carboxylic acids and chlorinated compounds. Linear combinations (roots) are constructed using the subset of the original observation file.

The canonical correlation coefficient between the two first roots is 0.96 showing that the first linear combination of sensor signals is linked to the emission of the selected compounds. Fig. 6 shows the evolution of that first combination of the sensor signals applied to the whole data set concerning the continuous signal monitoring for 11 days. The root value remains around zero unless during the 17th day when it goes beyond two: that is precisely a "stress" day, as the compost windrow was not turned for 5 days.

Fig. 6: Time evolution of the first root of a canonical correlation analysis calibrated with ammonia, nitrogen compounds, carboxylic acids and chlorinated compounds.

Time

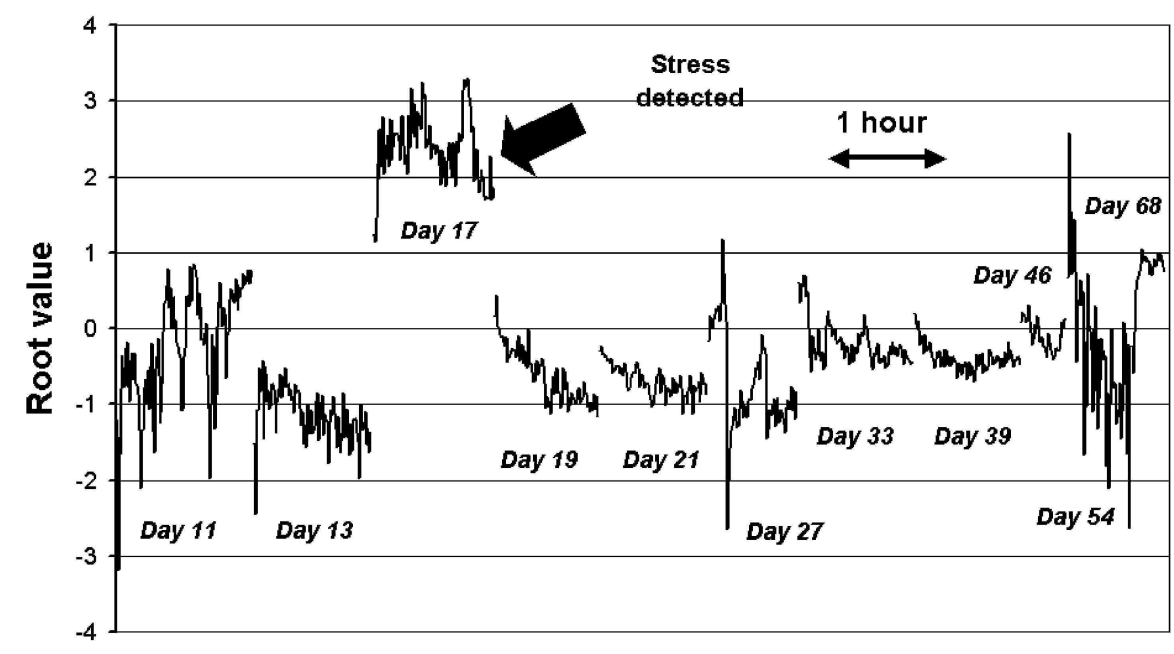

A second indicator is constructed by relating the sensor signals for the same subset of observations, this time to the compounds emitted during the "final" phase: furans and ketones. The canonical correlation coefficient between the two first roots is 0.91 . Fig. 7 shows the evolution of that root with time for the whole data set. The root value rises for day 68 , when the compost reaches the end of its composting phase.

Fig. 7: Time evolution of the first root of a canonical correlation analysis calibrated with furans and ketones.

Time

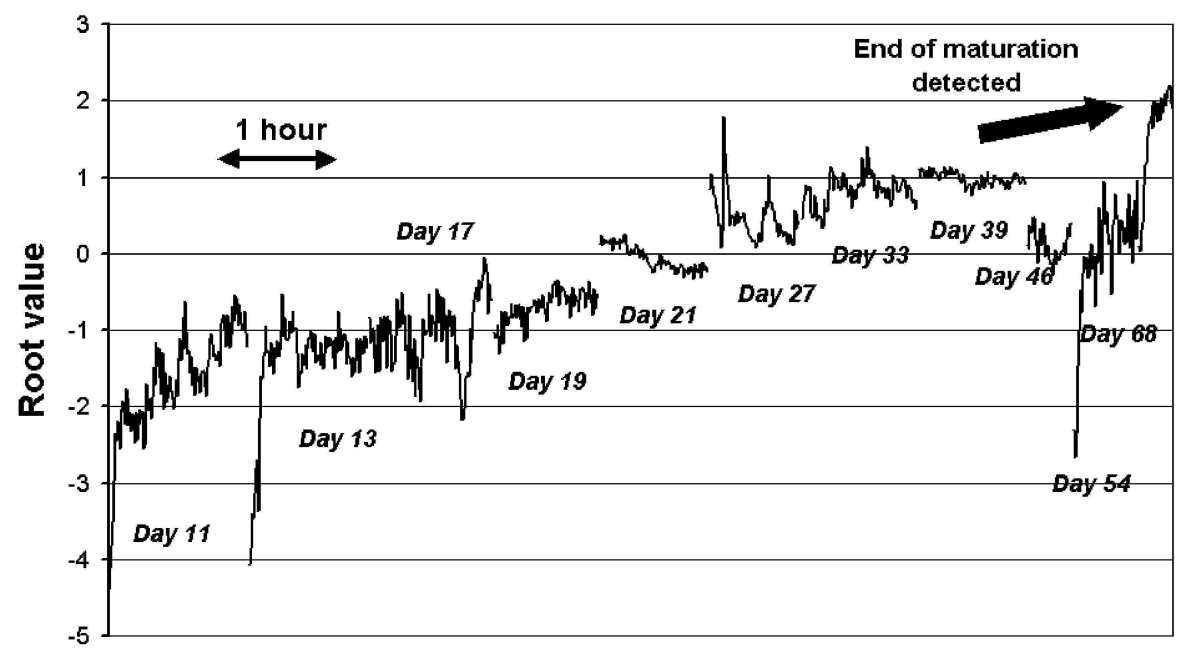


Thus, with the same sensor signals, different types of indicators can be constructed, depending on the type of event they intend to highlight. The calibration of such indicators just needs the results of a systematic GC-MS analysis, which is a one-shot operation. Once calibrated, the indicators could be used for on-line monitoring of the compost process.

\section{Discussions}

Chemical analyses confirm that the relative chemical composition of the emission of the compost pile is related to the process parameters (see 17th day, 21st day and the two last days). Good correlation between the TGS sensors and some chemical families is observed in the plane of the two first PCA components. Even if the alcohol family is the most abundant during the composting period (about $40 \%$ of the total), the variation of the relative composition of the emission (like emergence of nitrogen compounds and carboxylic acids with a respective relative value inferior to $10 \%$ ), can be detected by the e-nose thanks to the canonical functions. These results illustrate the interest of the non-specificity of the sensors and of the use of an array for the monitoring of complex mixtures.

To the question "is the e-nose able to "see" the events of the compost process and to identify them?", we respond yes. Anyway, we are aware that to enforce this answer, we should continue the measurements on new compost piles. Validation of the model with new data sets independent of the model should be done. But hopefully the continuous identification of composting events with the e-nose looks possible.

During this campaign, humidity and temperature in the sensors chambers were recorded but not regulated. In the TGS chamber, temperature was about $40{ }^{\circ} \mathrm{C}$, with a standard deviation of four and relative humidity was $26 \%$ with a standard deviation of two. Even if the variations of these operating conditions of the nose are small, they can highly influence the sensor signal ${ }^{[12,13]}$. A thermal control of the chambers is under development. Also a better handling of the emission dilution with dry air is required.

It is always essential to be conscious of the sensors constraints. Previous papers have shown that the drift effect has to be compensate and specially in harsh conditions ${ }^{[13,14]}$.

The lack of inter-changeability of the sensor in the same array is still a problem for environmental applications ${ }^{[13]}$.

Concerning the sampling, the area covered by the emission chamber represented only $0.4 \%$ of the total area of one of the two lateral sides of the pile. In that case it is assumed that this small part of the compost pile reacts like the whole pile. Indeed sampling on passive area sources still needs researches and standardization work ${ }^{[15]}$. Anyway the results illustrate that the emissions are well correlated to the parameters of the composting process.

\section{Conclusions}

The use of an e-nose to monitor the composting process is tested. The behaviour of the sensors confirms the physico-chemical trends. The TGS sensors are more correlated to the chemical composition of the compost exhaust air than the "Capteur" ones. The harsh conditions of this application have destroyed one of the sensors. But even in these conditions, the results obtained are satisfactory; e-nose is an easy tool for on-line control. Anyway, previously to routine operation, a calibration of the signals of the sensors with released chemical substances and process variables is required. These variables have to be known to allow the validation of the enose measurements. An emission chamber is then needed in the training and validation phase. In addition, in order to avoid the saturation of the sensors, it was imperative to dilute the emissions. Before to be implanted in the process, the design of the system has to be improved and the weaknesses of the gas chemical sensors (drift, reproducibility, robustness, temperature and humidity influences) have to be taken into account. But the advantages of the e-nose measurement for the management of the composting process in comparison with classical spotted measurements are real. In this paper, we highlight the ability of the e-nose to monitor various kinds of events simultaneously. Indeed, with the development of specific models, it is possible to monitor during the same time different parameters of the compost with the same instrument! 


\section{References}

[1] A.-C. Romain, J. Nicolas, V. Wiertz, J. Maternova, P. Andre, Use of a simple tin oxide sensor array to identify five malodours collected in the field, Sens. Actuators B: Chem. 62 (1) (2000) 73-79.

[2] H.T. Nagle, R. Gutierrez-Osuna, B.G. Kermani, S.S. Schiffman, in: J.W. Gardner (Ed.), Environmental Monitoring, Handbook of Machine Olfaction, Wiley-VCH, 2002.

[3] T. Page, C. Guy, Odor dispersion modeling, in: Proceedings of the Air and Waste Management Association's 90th Annual Meeting and Exhibition, Toronto, Canada, 8-13 June 1997.

[4] J. Nicolas, A.-C. Romain, D. Monticelli, J. Maternova, P. Andre, Choice of a suitable e-nose output variable for the continuous monitoring of an odour in the environment, ISOEN2000, Brighton, 2000.

[5] J. Nicolas, A.-C. Romain, J. Maternova, in: M.-T. Ramirez-Silva (Ed.), Chemometrics Methods for the Identification and the Monitoring of an Odour in the Environment with an Electronic Nose, Sensors and Chemometrics, Research Signpost, Kerala, 2001, pp. 75-90.

[6] M. Day, K. Shaw, M. Krzymien, Composting odours: what can chemistry tell us? in: Proceedings of the International Composting Symposium, Halifax/Dartmouth Nova Scotia, Canada, 19-23 September 1999.

[7] B. Beck-Friis, S. Smars, H. Jonsson, H. Kirchmann, Gaseous emission of carbon dioxide, ammonia and nitrous oxide from organic household waste in a compost reactor under different temperature regime, J. Agric. Eng. Res. 78 (4) (2001) 423-430.

[8] Y. Nobuyuki, J. Hoashi, T. Morita, Sj. Mc Niven, Monitoring of the composting process using a mediator-type biochemical oxygen demand sensor, Analyst 126 (2001) 1751-1755.

[9] T. Bachinger, J.E. Haugen, Process monitoring, in: J.W. Gardner (Ed.), Handbook of Machine Olfaction, Wiley-VCH, 2002.

[10] X. Wang, J. Jiang, R. Kaye, Improvement of a wind tunnel sampling system for odour and VOC's, Water Sci. Technol. 44 (9) (2001) 71-77.

[11] J. Müsken, Odours - primary and secondary odour sources in composting plants — design and management optimisation for odour prevention, in: Proceedings of the Effective Odour Management in Biological Waste Treatment Plants, International European Compost Network Workshop, Stadthalle Aschaffenburg, Germany, 20-22 March 2003.

[12] A.-C. Romain, J. Nicolas, P. Andre, In situ measurement of olfactive pollution with inorganic semiconductors: limitations due to humidity and temperature influence, Semin. Food Anal. 2 (1997) 283-296.

[13] J. Nicolas, A.-C. Romain, P. Andre, Applying the electronic nose in the environment: requirements for the sensors, in: Proceedings of the Third International Seminar on Semiconductor Gas Sensors (SGS 2002), Ustron, Poland, 19-22 September 2002.

[14] A.-C. Romain, J. Nicolas, Three years experiment with the same tin oxide sensor arrays for the identification of malodorous sources in the environment, Sens. Actuators B: Chem. 84 (2002) 271-277.

[15] Frechen, A new model for estimation of odour emissions from landfill and composting facilities, in: International Waste Management and Landfill Symposium, Sardinia, 1995.

\section{Biographies}

Anne-Claude Romain graduated in chemical sciences from the University of Liège (Ulg, Belgium) in 1992. She received the master in environmental sciences from the Fondation Universitaire Luxembourgeoise of Arlon (FUL, Belgium) in 1993. Since 1995, she is a searcher at the same university (FUL) and has been working on the development of a malodour detector. Currently, she finishes a $\mathrm{PhD}$ thesis on the application of the electronic nose concept to the monitoring of odours in the environment.

David Godefroid is an industrial engineer student at ISIL (Liège, Belgium) and carried out a work of end of studies at FUL about the monitoring of the exhaust air of a compost pile.

Jacques Nicolas is engineer in physics. He received his $\mathrm{PhD}$ degree in 1977 in surface physics in University of Louvain, Belgium. He joined Fondation Universitaire Luxembourgeoise (FUL, Arlon, Belgium) in 1979, where he worked first on solar energy. He is currently the leader of the department "Environmental Monitoring" at FUL and he gives lectures in the field of environmental parameter measurement. His main research interest is the development of odour and indoor air pollution detectors usable in the field.

Martyna Kuske is doctor of medicine from the University of Warsaw (1990). She received the master in environmental sciences in 1999 and the DEA from FUL in 2000. Since 2000, she works on mould detection by means of an electronic nose in the frame of a PhD thesis at FUL. 